THE EFFECTS OF BREAST CANCER ON INDIVIDUAL LABOUR MARKET OUTCOMES: AN EVALUATION FROM AN ADMINISTRATIVE PANEL

THOMAS BARNAY, MOHAMED ALI BEN HALIMA, EMMANUEL DUGUET, CHRISTINE LECLAINCHE, CAMILLE REGAERT 
ISSN 2110-5472 


\title{
The effects of breast cancer on individual labour market outcomes: an evaluation from an administrative panel ${ }^{*}$
}

\author{
Thomas Barnay ${ }^{1,2}$, Mohamed Ali Ben Halima ${ }^{3}$, Emmanuel Duguet ${ }^{1,2,3}$, \\ Christine Le Clainche ${ }^{4,3}$ and Camille Regaert ${ }^{5}$ \\ ${ }^{1}$ Université Paris Est, ERUDITE (EA 437) \\ ${ }^{2}$ FR TEPP CNRS 3435 \\ ${ }^{3}$ Centre d'Etudes de l'Emploi \\ ${ }^{4}$ Université de Lille 2, LEM (UMR CNRS 9221) \\ ${ }^{5}$ IRDES
}

September 2016

\begin{abstract}
Using an administrative data set (Hygie), we apply a difference-in differences with dynamic matching estimation method to the onset of breast cancer. The employment probability decreases by 10 percentage points (pp) one year after the onset of cancer compared to the not-treated group. The detrimental effect of breast cancer on employment increases significantly over time, by up to $12 \mathrm{pp}$ after five years. Another aim of our study is to identify some socio-demographic and work-related protective factors against the adverse effects of breast cancer on labour market outcomes. We stress four potential protective factors related to the negative effect of breast cancer. First, a young age at occurrence reduces this deleterious effect. Second, a high first job wage also appears to be a protective factor. Third, having faced less unemployment in the past is associated with a weaker negative effect of breast cancer on employment in the short run. Finally, we find a moderate "generational effect" after stratification by year of cancer onset.
\end{abstract}

JEL: : I10, J21, J22.

Keywords: breast cancer, labour market participation, difference in differences, matching.

\footnotetext{
* Corresponding author: Thomas Barnay, Université Paris Est, Mail des Mèches, 61 avenue du Général de Gaulle, 94010 Créteil Cedex, France. thomas.barnay@u-pec.fr
} 


\section{Introduction}

Thanks to advances in organized screening, detection and treatment, cancers may be related to chronic diseases (Cutler (2008)). Breast cancer imposes a substantial burden on the statutory health insurance in France. This cost burden impacts the long-term disease scheme, which supports all expenditures related to chronic diseases, including cancers. Therefore, the average cost of treatment for breast cancers in France is 10 thousand euros per year. In 2012, the expenditures on all cancers reached 14 billion euros, including 2.3 billion for breast cancer alone. In addition, breast cancer causes indirect costs: lost days of work and productivity losses (Rapport de l'observatoire sociétal des cancers (2014)). 1 In the female population, breast cancer exhibits an earlier onset than that of other cancers ${ }^{2}$ and requires treatments associated with functional sequels and therefore raises questions regarding the impact of breast cancer on individual well-being and, especially, labour market outcomes. Furthermore, the net survival rate of women diagnosed with breast cancer in France between 1989 and 2004, according to French cancer registries, is $97 \%$ after one year and $86 \%$ after five years (Jooste, Grosclaude, Remontet, Launoy, Baldi, Molinie, Arveux, Bossard, Bouvier, and Colonna (2013)), thus allowing the study of the causes of work impairment.

Effect of cancer on labour market outcomes. According to health capital models (Grossman (1972)), the onset of cancer, like any serious health event, affects career paths through the potential effects on the health stock, the decrease in productivity and in hours worked (Moran, Short, and Hollenbeak (2011)), the depreciation rate of health capital and the future investments in human capital. In a meta-analysis of 26 papers using US and European data, de Boer, Taskila, Ojajarvi, van Dijk, and Verbeek (2009) estimate the relative risk of unemployment of cancer survivors at 1.37 relative to the healthy population, all other things being equal. In a review of 64 international articles, Mehnert (2011) shows that the average return to work of cancer survivors increases from $40 \%$ six months after the diagnosis to $62 \%$ after twelve months, $73 \%$ after eighteen months and $89 \%$ after twenty-four months. Conversely, the onset of cancer also motivates permanent exits from the labour market. In Finland, after accounting for age and gender differences, the relative risk of early retirement is 2.2 for survivors of cancers of the nervous system, 2 for leukemia, 1.9 for tongue cancers, 1.2 for breast cancers and 1.1 for prostate cancer (Taskila-Abrandt, Pukkala, Martikainen, Karjalainen, and Hietanen (2005)). In a previous French study, we show that the onset of cancer decreases the probability of being employed by 7-8 percentage points (one year after cancer onset) and 13 percentage points (five years after), with the same proportions being observed for male and female populations (Barnay, Ben Halima, Duguet, Lanfranchi, and Le Clainche (2015)). The negative impact of cancer on the career path operates primarily through functional limitations (Bradley et al. (2002) USA),

which may be specific, such as arm pain for breast cancer, as a major sequel of treatment (Quinlan, Thomas-MacLean, Hack, Kwan, Miedema, Tatemichi, Towers, and Tilley (2009) in Canada, Blinder, Patil, Thind, Diamant, Hudis, Basch, and Maly (2012) in the USA), depressive episodes (Damkjaer, Deltour, Suppli, Christensen, Kroman, Johansen, and Dalton (2011) in Denmark) and memory and concentration disorders (Oberst, Bradley, Gardiner, Schenk, and Given (2010) USA). These effects are amplified or attenuated depending on the nature of the

\footnotetext{
${ }^{1} 153000$ new cases of breast cancer were estimated for 2011 . The death rate from breast cancer is 22.3 per 100 000 inhabitants in France, close to the OECD average of 20.1.

${ }^{2}$ The median age at breast cancer onset was approximately 65 years in France in 2012 (INCA (2015)). Cancer before age 40 represents $5 \%$ of the cases diagnosed. Diagnoses of new cases are generally made after 55 years of age, partly due to systematic screening from 50 years onward (INCA (2014)).
} 
initial endowments of human capital, the difficulty of pre-diagnosis working conditions, the type of cancer (site, severity of the disease) and, finally, the nature of the treatment (Johnsson, Fornander, Rutqvist, and Olsson (2011), Lindbohm, Kuosma, Taskila, Hietanen, Carlsen, Gudbergsson, and Gunnarsdottir (2011), Mujahid, Janz, Hawley, Griggs, Hamilton, Graff, and Katz (2011), Blinder et al. (2012)). Past professional biography (unemployment or training episodes) can also lead to stigmatizing effects on the careers of individuals (Heckman and Borjas (1980), Gregg and Tominey (2005)) and, for some social groups, predicts the occurrence of occupationrelated cancers. Feuerstein, Todd, Moskowitz, Bruns, Stoler, Nassif, and Yu (2010) thus stress the importance of improvements in the workplace in terms of schedule flexibility, social support from colleagues, social climate and job stress to protect working ability among cancer survivors.

Focus on Breast cancer. A large international literature (with a particular reliance on US data) is devoted to effect of breast cancer on professional paths (Chirikos, Russell-Jacobs, and Cantor (2002), Chirikos, Russell-Jacobs, and Jacobsen (2002), Drolet, Maunsell, Mondor, Brisson, Brisson, Masse, and Deschenes (2005), Bradley, Oberst, and Schenk (2006), Bradley, Neumark, and Barkowski (2013), Heinesen and Kolodziejczyk (2013)). For instance, Bradley, Neumark, Luo, and Bednarek (2007) show that the negative effect of cancer on employment significantly persists 6 months after the diagnosis but not more. Heinesen and Kolodziejczyk (2013) measure the causal effects of breast and colorectal cancer on labour market outcomes. On the basis of Danish administrative data, they estimate the ATT (average treatment effects on the treated) using propensity score methods with persons with no cancer as a control group. Suffering from breast cancer in year $t$ reduces the probability of being employed by 4.4 percentage points in year $t+1$, by 5.7 percentage points in year $t+2$, and 6.7 percentage points in $t+3$. From Danish data (2001-2009), Carlsen, Badsberg, and Dalton (2014) stress that women, after a breast cancer diagnosis, who experienced periods of unemployment before the diagnosis have an increased risk of being unemployed thereafter relative to women who worked before diagnosis (79 weeks of unemployment against 26 weeks for working women before diagnosis). Past French studies are more limited. Eichenbaum-Voline, Malavolti, Paraponaris, and Ventelou (2008) and Joutard, Paraponaris, Sagaon-Teyssier, and Ventelou (2012) apply a matching method to survey data that include treatment variables. Marino, Sagaon, Laetitia, and Anne-Gaelle (2013) show that two years after the diagnosis of cancer, the probability of returning to work in the female population is $72 \%$ (against $25 \%$ six months after the diagnosis).

Many articles underline the role of different health and socioeconomic characteristics that influence the effect of breast cancer on employment. First, a significant body of literature highlights the nature of cancer and types of treatment (Hassett, O'Malley, and Keating (2009), Jagsi, Hawley, Abrahamse, Li, Janz, Griggs, Bradley, Graff, Hamilton, and Kratz (2014)). Treatments require an exit from the labour market, which may be long when women undergo a combination of treatments (surgery, radiotherapy, and chemotherapy). In France, as in other developed countries, facing a combination of treatments (especially chemotherapy before and/or after radiotherapy) has the most detrimental effect on the speed with which a woman with breast cancer can return to work (for a French data set that includes the severity of the disease and the type of treatments, see Duguet and Le Clainche (2016)). Women who have undergone a surgery with partial mastectomy followed by radiotherapy can often return to work in the 6 months following the surgery, if no comorbidity occurs.

Treatment and comorbidity factors and sociodemographic and work-related characteristics may also explain differences in labour outcomes (Bradley, Neumark, Bednarek, and Schenk 
(2004), Torp, Gudbergsson, Dahl, Fossa, and Fløtten (2011)). Cross-country differences in the delays beyond 6 months may be explained by protective factors such as favourable social protection rules (sick leave legislation, social insurance schemes, work flexibility) and how employers are allowed to arrange working conditions. Using French data, Duguet and Le Clainche (2016) show that the probability of returning to work two years after diagnosis, especially for women diagnosed with breast cancer, increases when appropriate working conditions are implemented. Generally, the onset of cancer affects future investments in human capital (primary or secondary health prevention) due to the difficulty of combining work and cancer treatment (Yarker et al. (2010), Johnsson et al. (2011)). The onset of cancer can also modify the nature of the labour contract (e.g., full-time/part-time, working hours). Many studies shed light on the relationship between cancer occurrence and work duration (Farley, Vasey, and Moran (2008), Paraponaris, Teyssier, and Ventelou (2010), Petersson et al. (2011), Torp et al. (2011)). From a Swedish sample of 756 working women who have undergone breast cancer surgery, Petersson et al. (2011) find that, one month after the surgery, $56 \%$ of women with breast cancer are on sick leave, the majority full-time. Most of these women are employed at diagnosis, and $91 \%$ of them work greater than $75 \%$ of full-time. According to Farley, Vasey, and Moran (2008), in the USA, survivorship affected the probability of working full-time and hours worked for both genders 2-6 years post-diagnosis. In the female population of survivors after a new cancer diagnosis, the negative effects attributable to the cancer are 14 to $17 \mathrm{pp}$ (percentage points) for the employment rate, 14 to $18 \mathrm{pp}$ for full-time employment and 7 to 8 for hours worked per week. Torp et al. (2011), using a Norwegian database, highlight that a low socioeconomic position appears to be a risk factor for returning to work. On the basis of Korean data (1993-2002), after a breast cancer diagnosis, working women are more frequently unemployed if they have low education or a low income (Eunmi, Cho, Shin, Park, Ahn, Noh, Nam, Lee, and Yun (2009)).

Using French data, Paraponaris, Teyssier, and Ventelou (2010) study the relationship between cancer occurrence and the type of labour contract. Their findings indicate that fixedterm contracts exhibit greater risk of job loss for workers in the female population (-8 pp relative to permanent contracts).

From a theoretical perspective, the return to work depends on economic incentives. Bradley, Neumark, and Barkowski (2013) demonstrate that the negative effect of breast cancer on employment is reduced if the patient's health insurance is dependent on the job. This result refers to the "job lock" assumption, i.e., workers remain in their current job to maintain their health insurance. In contrast to the USA, in France, for particular diseases that require intensive, expensive and long-term care (such as cancer), the long-term disease scheme has been implemented to pay for the related treatment costs and provide equal access to health care.

In this study, we focus on the sociodemographic and work-related aspects of cancer. Given the French legal framework, we cannot assume a job lock effect. We expect that the negative effect of breast cancer will persist over time even if the woman does not suffer from a recurrence of the disease, as in Heinesen and Kolodziejczyk (2013) in the Danish case.

We examine four potential types of socioeconomic factors that could influence employment in the short and long term. First, breast cancer occurring at a younger age could be less disadvantageous than at a later age (Petersson (2011)). Second, a strong socioeconomic position is associated with appropriate working conditions following diagnosis and with a better return to work (Eunmi et al. (2009)). Third, we account for the stability of the past career before the onset of cancer (Heckman and Borjas (1980), Gregg and Tominey (2005)). Finally, we also examine a generational effect. Advances in medicine coud lead to a better return to work for 
the most recent generation of cancer survivors, but other factors, such as discrimination ${ }^{3}$ in the labour market, could play a more ambiguous role.

Using panel data from the National Pension Fund and the National Health Insurance Fund, we examine two issues. First, we estimate, for the first time in France, the effects of breast cancer on employment outcomes up to five years after its onset. We perform a difference-indifferences analysis combined with a dynamic matching algorithm. Second, we highlight the role of protective factors that attenuate the adverse effects of cancer on labour market outcomes. The paper is organized as follows. Section 2 is devoted to the methodology and the econometric model specifications. In section 3, we present our main findings, and a discussion is provided in section 4 . The final section presents our conclusions.

\section{Data and methodology}

Data. The HYGIE data set was constructed from two nationwide administrative sources. The HYGIE data were extracted from the National Pension Fund (CNAV) and the National Health Insurance Fund for Salaried Workers (CNAMTS) administrative databases. The resulting database contains individual information on beneficiaries, their professional careers, medical consumption, sick leave, employees' professional context and a few characteristics concerning employer establishments. The HYGIE database makes it possible to study the relationships among health, work, professional career and firm characteristics. HYGIE is representative of private sector employees in France.

Specifically, the files were extracted from the National Career Management System (SNGC), which groups all private sector employees in France, and the National Statistical Beneficiaries System (SNSP), which groups all private sector retirees in France, matched with sickness benefit data taken from the National Health Insurance Inter-regime Information System (SNIIRAM). The CNAV data constituted the point of entry and included a random sample of beneficiaries aged 22 to 70 years who contributed to the general pension fund at least once in their lives. The CNAMTS data concern both primary and secondary beneficiaries of the National Health Insurance scheme who received sickness benefits for at least one health service in 2003, 2004 or 2005. The linkage of the CNAV and CNAMTS data enabled us to construct the HYGIE database panel of 538,870 beneficiaries from 2005 to 2010 .

There are 552,048 working people in these data. Restricting to women leaves $225,340 \mathrm{ob}-$ servations. For this study, we use a data set that includes the entire career of the workers from their first job to the year 2008. We drop the retirement years and retain only the active period to evaluate the impact of cancer on employment. The demographic data include gender and birth year. The HYGIE data include the wage from the first job. We take the ratio of this first job wage to the yearly median wage and compute four equally sized initial wage classes. This approach corrects for inflation and indicates a worker's position in the income distribution.

The medical data include a sick leave dummy and the International Statistical Classification of Diseases and Related Health Problems (henceforth, ICD). We identify breast cancer with ICD code C50. To implement the dynamic matching methodology, we retain all the women in the sample, that is, women with breast cancer, women with no disease and women with another disease. These other diseases include all other cancer types and the French definition of longterm diseases (such as diabetes).

\footnotetext{
${ }^{3}$ Paraponaris, Teyssier, and Ventelou (2010) highlight the endogeneity of discrimination for female survivors after cancer. They underline that productivity or number of children could contribute to a decrease in the return to work through the effect of perceived discrimination.
} 
These diseases are on an official list and must last at least 6 months. They are fully financed by the statutory health insurance. Our approach also guarantees that the estimation results obtained for all of the cancers and diseases in this data set are comparable, as the same data set can be used for all of them.

Three labour market statuses were identified in the HYGIE data: employment, regular employment and unemployment. The outcome variables indicating the individual's employment status were identified in the HYGIE database on the basis of contributions paid for qualifying periods (unemployment, sickness/occupational accident) and quarters of national social security scheme contributions. Individuals were thus identified as follows. Regular employment means at least one quarter of contribution to the national social security system and the absence of unemployment spells. Employment means at least one quarter of contribution, with or without unemployment spells.

We use the following indicator of career stability. We divide the number of years with an unemployment spell by the total number of years spent in the labour market. We match women on the value of this indicator one year before cancer onset to control for their past labour market performance. We use the same type of indicator for past health: the number of years with sickness leave divided by the total number of years spent in the labour market. We also use the lagged value of this indicator (one year before cancer) when we match women.

To implement the dynamic matching methodology, we retain all the women in the sample, again, women with breast cancer, women with no disease and women with a disease other than breast cancer. These other diseases include all other types of cancer and all of the diseases that correspond to the French definition of long-term diseases (such as diabetes). These diseases are on an official list, and must last at least 6 months. They are fully financed by the compulsory health insurance scheme. This approach also guarantees that the results obtained for all of the cancers and diseases in the data set are comparable, as the same data set can be used for all of them.

Methodology. Our estimator is similar to that of Heckman, Ichimura, and Todd (1997). We wish to explore the impact of breast cancers on the employment history of women. We account for four estimation issues. First, cancer is likely to cause a break in individual employment histories. In this case, only a dynamic approach can identify the break with a before-after analysis, where the break date is the date of the cancer and is specific to each individual. A static approach can only compare individuals with different health status at the date of the survey and cannot directly analyse the impact of cancer for each individual. Second, the women in the data set have different ages, and hence the observation window differs across women. Therefore we need to match women by age to ensure that we compare women who had a health event (or did not) at the same age and during the same year. Third, we account for the fact that the panel data model includes correlated individual and time effects. We also allow for heterogeneous time trends by adding matching to the usual difference-in-differences estimator. Fourth, we perform a non parametric estimation, and hence no specific distributional assumption is made.

In the standard difference-in-difference approach (henceforth, DiD; see Lee (2003) for details), the variables that are constant over time should not alter the estimations, which should allow this approach to control for individual-level unobserved heterogeneity. Our approach generalizes $\mathrm{DiD}$ in two directions. First, we match on the lagged endogenous variables such that we compare women who had comparable labour market situations before the health event. This allows for a better assessment of the health-labour causality because the women in our 
cancer group have the same occupation as the women in the control group before the health event occurs. Therefore, we can rule out reverse causality from labour to health, as the women who work more often are matched with similar women in the control group. Second, the standard DiD method assumes that the time effects share parallel trends in the health-event group and in the control group. By matching on individual characteristics, we allow for the time trends to differ between the health-event and control groups, to the extent that the slopes of the trends depend on the individual characteristics and the lagged endogenous data. For these reasons, our application of DiD should provide a more robust estimation than in the standard case.

The Hygie data set provides a detailed, dynamic account of two main variables: cancer occurrence and occupational status. In this section, we analyse how it is possible to evaluate the impact of cancer on subsequent labour market history. To successfully identify the impact of health events, we need to account for two types of quantities: on one hand, the difference in histories between those women who experienced cancer and other women and, on the other hand, the variations in the labour history of one woman before and after cancer. In this section, we show that the DiD method with matching allows us to estimate the effect of cancer by controlling both for the observable individual variables and unobservable individual heterogeneity, including when the latter is correlated with the observable individual variables.

The outcome variables are the annual activity dummies corresponding to the three following occupational statuses: employment, unemployment and sick leave. One can interpret our analysis as an assessment of the impact of breast cancer on these occupational dummies.

We consider all the women with breast cancer, denoted $i \in I$, where $I$ stands both for the index set of the women with breast cancer and their number. A woman $i \in I$ is observed between the years $t_{i}^{-}$and $t_{i}^{+}$, and a breast cancer diagnosis occurs in year $t_{i} \in\left(t_{i}^{-}, t_{i}^{+}\right)$. To evaluate the effect of the cancer, we compare the occupation of woman $i$ in $t_{i}-1$ to the occupational choice $k$ years after the health event, in $t_{i}+k \leq t_{i}^{+}$. In what follows, we take employment as example, but any other occupational status can be treated in the same manner. The employment probability of woman $i$ during year $t$, denoted $p_{i, t}$, depends on a vector of individual explanatory variables $X_{i}$, an unobservable individual effect $\alpha_{i}$, potentially correlated with $X_{i}$, a time effect $\beta_{0, t}$ and a joint effect of the explanatory variables with the time effect $\beta_{1, t}\left(X_{i}\right)$. The employment dummy variable $d_{i, t}$ follows a Bernoulli process with mean $p_{i, t}$ given by

$$
\begin{aligned}
& d_{i, t}=p_{i, t}+\epsilon_{i, t} \\
& p_{i, t}=f_{i}\left(X_{i}\right)+\alpha_{i}+\beta_{0 t}+\beta_{1, t}\left(X_{i}\right)+\gamma_{i}\left(t-t_{i}\right) \times T_{i, t}
\end{aligned}
$$

where $f_{i}\left(\right.$.) is an unknown function relating $X_{i}$ to the employment probability $p_{i, t}, \gamma_{i}$ is the effect of the breast cancer on the probability of being employed, and $T_{i, t}$ a dummy variable equal to 1 if there is a breast cancer $\left(t \geq t_{i}\right), 0$ otherwise $\left(t<t_{i}\right)$. The $\gamma_{i}$ terms depend on how much time passed since the breast cancer occurred $t-t_{i}$. The $\epsilon_{i, t}$ terms are idiosyncratic error terms with $\mathrm{E}\left(\epsilon_{i, t} \mid X_{i}, \alpha_{i}, \beta_{0 t}, \beta_{1 t}\left(X_{i}\right), T_{i, t}\right)=0$. Henceforth, we consider the effect of the cancer between $t_{i}-1$ and $t_{i}+k$, and thus, we wish to estimate an average value for $\gamma_{i}(k), k \geq 1$.

The estimation proceeds through the elimination of all the components except $\gamma_{i}(k)$. The techniques used to achieve this goal are based on differencing (for $\alpha_{i}$ and $\beta_{0, t}$ ), matching (for $X_{i}$ and $\beta_{1, t}\left(X_{i}\right)$ ) and averaging (for $\epsilon_{i, t}$ ). In the first step, we will match the women experiencing a cancer $(i \in I)$ with their (statistical) twins as follows:

$$
J(i)=\left\{j: t_{j}^{-} \leq t_{i}-1, t_{i}+k \leq t_{j}^{+}, t_{j}>t_{i}+k \text { and } X_{j}=X_{i}\right\}
$$


the two first inequalities simply require that the twins be present over the same period as woman $i$. The third inequality defines dynamic matching, the twins in $J(i)$ should experience their cancers (or another long-term disease, if any) after the end of the comparison period for woman $i$. This implies that we match $i$ with, on one hand, women who will neither experience cancer nor another long-term disease and, on the other hand, women who will experience either cancer or another long-term disease at a later date. When someone does not experience cancer (or another long-term disease), we use the convention $t_{j}=\{+\infty\}$. Ultimately, the matched individuals should have the same individual characteristics. The notation $J(i)$ will also be used to indicate the number of twins matched with woman $i$. Note that two women can share common twins, as we make use of all potential matches for each woman. By definition, the outcome variable of the pair does not include the effect of the cancer, and hence the pair's outcome variable is given by

$$
\begin{aligned}
& d_{j, t}=p_{j, t}+\epsilon_{j, t} \\
& p_{j, t}=f_{j}\left(X_{j}\right)+\alpha_{j}+\beta_{0 t}+\beta_{1, t}\left(X_{j}\right)
\end{aligned}
$$

and the average outcome of $i$ 's twins is given by

$$
\frac{1}{J(i)} \sum_{j \in J(i)} d_{j, t}=\beta_{0 t}+\beta_{1, t}\left(X_{i}\right)+\frac{1}{J(i)} \sum_{j \in J(i)}\left(f_{j}\left(X_{i}\right)+\alpha_{j}+\epsilon_{j, t}\right)
$$

Consider first the difference between woman $i$ and all her matches $j \in J(i)$ before the health event; we eliminate the terms in $\beta_{0, t_{i}-1}$ and $\beta_{1, t_{i}-1}\left(X_{i}\right)$ and obtain the following:

$$
\begin{aligned}
D_{i, t_{i}-1} & =d_{i, t_{i}-1}-\frac{1}{J(i)} \sum_{j \in J(i)} d_{j, t_{i}-1} \\
& =f_{i}\left(X_{i}\right)+\alpha_{i}+\epsilon_{i, t_{i}-1}-\frac{1}{J(i)} \sum_{j \in J(i)}\left(f_{j}\left(X_{i}\right)+\alpha_{j}+\epsilon_{j, t_{i}-1}\right)
\end{aligned}
$$

and when we take the difference after the cancer date, we also eliminate the $\beta$ components:

$$
\begin{aligned}
D_{i, t_{i}+k}= & =d_{i, t_{i}+k}-\frac{1}{J(i)} \sum_{j \in J(i)} d_{j, t_{i}+k} \\
& =f_{i}\left(X_{i}\right)+\alpha_{i}+\gamma_{i}(k)+\epsilon_{i, t_{i}+k}-\frac{1}{J(i)} \sum_{j \in J(i)}\left(f_{j}\left(X_{i}\right)+\alpha_{j}+\epsilon_{j, t_{i}+k}\right)
\end{aligned}
$$

the $\mathrm{DiD}(2)$ and (1) therefore leads to

$$
\begin{aligned}
D D_{i}(k) & =D_{i, t_{i}+k}-D_{i, t_{i}-1} \\
& =\gamma_{i}(k)+\epsilon_{i, t_{i}+k}-\epsilon_{i, t_{i}-1}-\frac{1}{J(i)} \sum_{j \in J(i)}\left(\epsilon_{j, t_{i}+k}-\epsilon_{j, t_{i}-1}\right)
\end{aligned}
$$

such that $\mathrm{E}\left(D D_{i}(k)\right)=\gamma_{i}(k) \forall i, k$. Our estimator is simply the average of these individual health effects. We define

$$
\hat{\gamma}(k)=\frac{1}{I} \sum_{i \in I} D D_{i}(k)
$$

such that

$$
\mathrm{E}(\hat{\gamma}(k))=\frac{1}{I} \sum_{i \in I} \gamma_{i}(k) .
$$

It remains to compute the variance of $\hat{\gamma}(k)$. The method is explained in the appendix. We performed the estimation with SAS 9.4. 
TABLE 1. Sample statistics.

\begin{tabular}{lccc}
\hline Variable & No chronic disease & Breast cancer & Difference \\
\hline$a \leq 35$ & $32.6 \%$ & $2.1 \%$ & $+30.5 \%$ \\
$35<a \leq 45$ & $27.8 \%$ & $11.4 \%$ & $+16.4 \%$ \\
$45<a \leq 55$ & $19.0 \%$ & $30.4 \%$ & $-11.4 \%$ \\
$a>55$ & $20.6 \%$ & $56.1 \%$ & $-35.5 \%$ \\
\hline$r \leq \mathrm{Q}_{1}$ & $23.9 \%$ & $25.5 \%$ & $-1.6 \%$ \\
$\mathrm{Q}_{1}<r \leq \mathrm{Me}$ & $25.2 \%$ & $20.1 \%$ & $+5.1 \%$ \\
$\mathrm{Me}<r \leq \mathrm{Q}_{3}$ & $25.4 \%$ & $23.6 \%$ & $+1.8 \%$ \\
$r>\mathrm{Q}_{3}$ & $25.5 \%$ & $30.9 \%$ & $-5.4 \%$ \\
\hline
\end{tabular}

Note: $a$ : age in 2008. $r$ : first job relative income class.

\section{Results}

Our sample includes 2,547 women who suffer from a breast cancer for enough years to compute a before-after difference. These women will be matched with 203,392 women with no long-term (six months) disease and 19,059 women with another long-term disease. Overall, women who experienced breast cancer have similar incomes to the others. They are somewhat less represented in the highest income class. They are also significantly older, as expected. In $2008,60.4 \%$ of women with no disease were less than 45 years old, while only $13.5 \%$ of women with a breast cancer were under 45 (Table 1).

We use a matching method to eliminate the effect of the confounding variables on this naive average difference in outcome. We then perform five estimations (full sample; by age of cancer onset (more or less than the median age of 48); by first wage classes (in quartiles); by the stability of the professional career (measured with the indicator $(c)$, which represents the share of the number of years worked with at least one unemployment spell over the number of years worked, and three classes are selected $c=0$, low unemployment $(0<c \leq 0.16)$ and high unemployment $(c>0.16)$ ); and by onset year with three classes $(t \leq 1990,1991 \leq t \leq$ 1999 and $t \geq 2000$ ), thus allowing us to measure short- (one year) and long-term ( 2 to 5 year) breast cancer effects on two labour market outcomes (employment and regular employment, e.g., without unemployment spells).

Effects on employment. We use two indicators of employment. The first indicator is a dummy variable equal to one when a worker has validated at least one quarter in employment. We call this "employment" because it is representative of a job drawn at random from the total population. This definition includes all types of jobs: stable jobs but also insecure jobs and some quarters of unemployment or disease in the same year. To better assess the effect of breast cancer, we also use a more restrictive definition of employment "regular employment". Here, we require that there is no unemployment during the same year. Note that both definitions of employment are compatible with fixed-term contracts, and hence the "regular employment" jobs need not be especially stable over time. This indicator simply identifies workers who have been working during the year without experiencing unemployment.

The employment probability decreases by $9.8 \mathrm{pp}$ one year after the onset of cancer relative to the not-treated group (Table 2). We also observe that the detrimental effect of breast cancer on employment significantly increases over time, reaching $12.1 \mathrm{pp}$ five years later. If we 
consider regular employment (without unemployment spells), the adverse effect remains but is less pronounced (from $6.3 \mathrm{pp}$ in $t+1$ to 10.5 in $t+5$ ). At this stage, we can assume that the regular employment variable selects a protected population because such individuals better cope with the negative effects of a breast cancer on the career path.

A young age of occurrence. We compare the effect of cancer depending on the age of the worker at the onset of breast cancer. For workers under 48 (the median age at cancer onset in our data), the negative impact of a breast cancer remains constant over time (between 8 and 10 $\mathrm{pp}$ for irregular employment, $7 \mathrm{pp}$ for permanent employment), whereas this impact increases linearly in the older female population (above 48), from $8.4 \mathrm{pp}$ to $15.2 \mathrm{pp}$ for employment and from 5.2 to $13 \mathrm{pp}$ for regular employment. These patterns suggest that late cancer onset is more detrimental to the employment of breast cancer survivors, with a negative effect that increases over time. This pattern should be explored in depth and is likely due to opposite effects. Indeed, from a medical perspective, breast cancers at a younger age (before menopause) are known to be more aggressive, everything being equal, than a cancer onset occurring after menopause (after the mean age of 51 in France) $4^{4}$

Early cancers are often diagnosed with delay due to the absence of screening programmes and the low prevalence of the desease in that age range (less than $5 \%$ of breast cancers occur before 40). Moreover, early cancers usually receive a worse prognosis. Furthermore, we can assume that the young women may have more "energy" to return to work earlier than do older women, who also tend to be more discriminated against. However, several alternative explanations might account for the consequences of a patient's age at cancer onset. First, the nature of comorbidities and treatments might differ depending on the age of occurrence. Second, breast cancer occurring at older ages can be especially disabling and prevent women from maintaining a job (undergoing hormonotherapy, which is more frequently applied for post-menopausal women, is given for five years and often entails unpleasant side effects). Third, as more women approach retirement age, the opportunity cost of exiting employment decreases. Fourth, the decline in the probability of employment for older women may be explained by the "double penalty" phenomenon that can lead to amplified effects of exiting the labour market. Traditional analyses of investments in human and health capital can be enhanced by accounting for changes in preferences or age-related discrimination, which has been particularly noted for older workers (e.g., Datta Gupta and Larsen (2010)).

High income effect. We test the protective role of initial income on the negative impact of breast cancer on employment by dividing the sample into four classes (relative wage at the date of labour market entry) ${ }^{5}$ Our findings show that workers in the upper relative wage class (above the third quartile of the relative wage) are especially protected (Table 3). The negative effect of cancer varies from 3 to $12 \mathrm{pp}$ only, while it is considerably larger for other workers (under both employment measures). The decrease in the employment rate in the lowest relative wage class tends to increase over time from $10 \mathrm{pp}(t+1)$ to $18 \mathrm{pp}(t+5)$. This detrimental effect of cancer increases over time for all wage classes. The effect of cancer is strictly decreasing with

\footnotetext{
${ }^{4}$ Cancers at a young age are more often "triple negative," which prevents the use of efficient treatments. Hormonotherapy for hormonodependent cancer treatments is more effective after menopause than before, and the neo-adjuvant therapy for non-hormonodependent cancers is not considered effective (see, e.g., Pourquier (2000)).

${ }^{5}$ The relative wage is equal to the ratio of the entry wage to the median entry wage in the same year. Four classes are defined by the quartiles of this variable, which is defined for all workers. Notice that the quartiles are not computed based on the cancer population but on the total population.
} 
the relative wage class from the first to the third year after the onset of cancer. For instance, for employment, the effects after one year are - 15 pp, -12 pp, -9.3 pp and $-4.7 \mathrm{pp}$. Several arguments can explain these results. First, the French social protection system is highly redistributive and allows lower income workers to secure a better income replacement rate than higher income workers. This may create an inactivity trap that would explain the long term effect of $-17 \mathrm{pp}$ for the first quartile. Second, the lower wage class workers are more often affected by comorbidities associated with poor working conditions and tend to exit the labour market permanently. Third, the lowest quartile workers cannot easily benefit from work arrangements because the nature of their jobs makes doing so difficult.

Career stability. We test another assumption related to the nature of the past career (measured by the occurrence of unemployment spells in past years). The results show that employment and regular employment both decrease by 5 pp one year after breast cancer for women without any past unemployment spells. This short-term effect is greater for individuals who were unemployment in the past. Workers with a low past unemployment rate face a $11 \mathrm{pp}$ decrease in employment, while those with a high past unemployment rate (above $16 \%$ ) face a 16.6 pp decrease. However, this result does not extend to regular employment, as all workers with past unemployment spells face a 8 pp decrease one year after the onset of cancer. When comparing the outcome over a longer horizon, we obtain different findings with respect to stability class. People with a low past unemployment rate face a stronger decrease in their regular employment rate than do workers with the highest past unemployment rates. This could indicate the following dynamics: people with a low past unemployment rate would be more frequently driven toward unemployment and transition into a higher unemployment class in the future. Our findings indicate that for individuals who had previous unemployment spells, it is more difficult to remain in regular employment after a cancer shock.

A generational effect. The last test concerns a potential generational effect. We consider the impact of expected medical advances on the time to return to work for young. To test this hypothesis, we perform the estimation by onset year and consider short and medium terms (from $t+1$ to $t+3$ ). In the year following the diagnosis, the decline in irregular employment is very similar whatever the onset year (about 9-10 pp), which appears to contradict the innovation assumption. Nevertheless, we stress the clear generational effect we observe concerning the effect on regular employment. For a cancer diagnosis that occurred after 2000, the decrease in employment is $5.2 \mathrm{pp}$ versus $6.2 \mathrm{pp}$ between 1990 and 2000 and $9.3 \mathrm{pp}$ if the cancer appears before 1990. The gap between generations is corroborated for two and three years after cancer onset. The decline in employment for the new generation can be explained by several factors. The improvement in medical treatments for cancer in recent years could support this effect. The incidence of in situ cancers increased significantly from 1990 to 2005 in all age groups but particularly among 50 to 74 -year-old women. This trend reversed after 2005 . The incidence of invasive cancers grew slowly from 1990 to 1996 and then more sharply beginning in 1996, primarily among women aged 50-74 years, before declining in 2004. Finally, cancers in an advanced stage at diagnosis decreased after a peak in the early 2000s. Changes in incidence likely reflect the combined influence of several factors (risk factors, screening and diagnostic techniques). In addition, organized mammography screening for breast cancer was widespread in France in 2004. This programme allows all women aged 50 to 74 to have a mammogram and a clinical breast exam once every two years. Thus, for breast cancer, the 5 -year survival increased from $81 \%$ in 1990 to $89 \%$ in 2002. 


\section{Discussion and conclusion}

Our study is original in several respects. First, the estimation of the effect of cancer on professional situations covers a long-term period from one to five years after diagnosis. In addition, it relies on administrative data to identify the careers of a large sample of private sector employees. Moreover, the sample size permits performing a DiD analysis with exact matching and defining a rigorous control group that exploits the panel dimension of the data. Finally, we examine a relatively young female population (in our sample, $43 \%$ of the women with a breast cancer are less than 45 years of age), which reinforces the relevance of the analysis of career paths of this population.

Our main findings confirm, for the first time in France using this econometric method, the detrimental effect of breast cancer on employment. The proportion of individuals who have completed at least one quarter of employment decreases substantially after the onset of cancer: by $10 \mathrm{pp}$ after one year, and the effect is long-lasting because it remains at $12 \mathrm{pp}$ five years after cancer onset.

It is obviously difficult to compare our results with those of other studies because of the differences in data and methods and cross-country differences in labour market structure, public financing of cancer's cost and sick leave. Bearing this in mind, our findings are similar to those of Moran, Short, and Hollenbeak (2011) and Heinesen and Kolodziejczyk (2013), who use similar econometric methods by combining DiD and propensity score matching. Using Danish administrative register data, Heinesen and Kolodziejczyk (2013) estimate the effects of breast cancer on labour market outcomes for three-year survivors. Using two different control groups, they find following probabilities of decreased employment: $4.4 \mathrm{pp}$ in $t+1,5.3-5.8 \mathrm{pp}$ in $t+2$ and 6.2-6.7 pp in $t+3$.

Using US data, Moran, Short, and Hollenbeak (2011) focus on a young population, as our study does (cancer at younger ages, 28-54 years) and estimate the effect of surviving cancer on long-term employment outcomes (2-6 years post-diagnosis). Breast cancer survivors had employment rates that were 7-8 pp lower than the control group. These findings are significantly lower than ours. In general, the generosity of the French health insurance system can explain the more common occurrence of inactivity.

The originality of our study is to focus on many demographic and professional characteristics as protective factors against the deleterious effects of breast cancer on employment. As expected, a young age of occurrence, a high initial wage class and past employment stability promote a better return to work (similar to the results of Heinesen and Kolodziejczyk in 2013). Many studies identify social gradients in breast cancer survivors (e.g., Carlsen et al. (2008)).

Nevertheless, the most interesting findings concern the potential generational effect related to the medical advances. This result should be explored in greater depth.

Finally, several limitations of our study should be noted. In addition to that related to the definition of cancer (specific to this study), the data do not allow the identification of the cancer stage, the type of treatment or the severity. Before the Cancer Plan, which was adopted in France in 2004, that is during the common period of our study, an hypothesis can be made regarding the existence of a link between the aggressiveness of treatments (that is with significant pain and potentially adverse long-term side effects) and social gradients. Indeed, due to improved prevention behaviours, upper-income-class women are often better diagnosed and at an earlier stage of their cancer and can therefore recover without as much recurrence. However, this holds only for the older women (who are also benefiting from organized cancer screening programmes). 
TABLE 2. Effect of a breast cancer (C50), time-related conditioning. Difference-in-differences with dynamic matching estimates. Matching variables: lagged outcome dummies (employment, unemployment, disease), year of birth (exact), first job relative income class ( $r, 4$ levels), past disease class ( 3 levels), past unemployment class ( $c, 3$ levels).

\begin{tabular}{|c|c|c|c|c|c|c|c|c|c|}
\hline \multirow{2}{*}{$\begin{array}{l}\text { Time } \\
\text { after } \\
\text { event }\end{array}$} & \multirow[b]{2}{*}{ Treated } & \multirow[b]{2}{*}{ Matched } & \multirow[b]{2}{*}{ \# twins } & \multicolumn{3}{|c|}{ Employment } & \multicolumn{3}{|c|}{ Without unemployment } \\
\hline & & & & $\begin{array}{l}\text { Treated } \\
\text { lagged }\end{array}$ & ATT & ASE & $\begin{array}{l}\text { Treated } \\
\text { lagged }\end{array}$ & ATT & ASE \\
\hline Full sample & & & & $t_{i}-1$ & & & $t_{i}-1$ & & \\
\hline$t_{i}+1$ & 2547 & $100.0 \%$ & 605 & 0.861 & $-0.098^{*}$ & 0.005 & 0.765 & $-0.063^{*}$ & 0.005 \\
\hline$t_{i}+2$ & 2221 & $100.0 \%$ & 576 & 0.868 & $-0.087^{*}$ & 0.005 & 0.771 & $-0.071^{*}$ & 0.006 \\
\hline$t_{i}+3$ & 1934 & $100.0 \%$ & 557 & 0.873 & $-0.088^{*}$ & 0.006 & 0.777 & $-0.076^{*}$ & 0.006 \\
\hline$t_{i}+4$ & 1644 & $99.9 \%$ & 526 & 0.877 & $-0.094^{*}$ & 0.006 & 0.785 & $-0.090^{*}$ & 0.007 \\
\hline$t_{i}+5$ & 1410 & $100.0 \%$ & 494 & 0.878 & $-0.121^{*}$ & 0.007 & 0.783 & $-0.105^{*}$ & 0.008 \\
\hline Age at cancer $\leq 48$ & & & & $t_{i}-1$ & & & $t_{i}-1$ & & \\
\hline$t_{i}+1$ & 1310 & $100.0 \%$ & 684 & 0.897 & $-0.101^{*}$ & 0.006 & 0.800 & $-0.065^{*}$ & 0.006 \\
\hline$t_{i}+2$ & 1185 & $100.0 \%$ & 644 & 0.900 & $-0.075^{*}$ & 0.006 & 0.806 & $-0.064^{*}$ & 0.007 \\
\hline$t_{i}+3$ & 1100 & $100.0 \%$ & 617 & 0.899 & $-0.060^{*}$ & 0.006 & 0.802 & $-0.055^{*}$ & 0.007 \\
\hline$t_{i}+4$ & 986 & $100.0 \%$ & 583 & 0.901 & $-0.057^{*}$ & 0.007 & 0.811 & $-0.057^{*}$ & 0.008 \\
\hline$t_{i}+5$ & 892 & $100.0 \%$ & 555 & 0.896 & $-0.080^{*}$ & 0.008 & 0.805 & $-0.070^{*}$ & 0.009 \\
\hline Age at cancer $>48$ & & & & $t_{i}-1$ & & & $t_{i}-1$ & & \\
\hline$t_{i}+1$ & 1237 & $100.0 \%$ & 514 & 0.822 & $-0.084^{*}$ & 0.006 & 0.729 & $-0.052^{*}$ & 0.007 \\
\hline$t_{i}+2$ & 1036 & $100.0 \%$ & 486 & 0.822 & $-0.083^{*}$ & 0.008 & 0.731 & $-0.062^{*}$ & 0.008 \\
\hline$t_{i}+3$ & 834 & $100.0 \%$ & 464 & 0.830 & $-0.102^{*}$ & 0.009 & 0.745 & $-0.082^{*}$ & 0.010 \\
\hline$t_{i}+4$ & 658 & $100.0 \%$ & 432 & 0.839 & $-0.116^{*}$ & 0.010 & 0.749 & $-0.111^{*}$ & 0.011 \\
\hline$t_{i}+5$ & 518 & $100.0 \%$ & 390 & 0.849 & $-0.152^{*}$ & 0.011 & 0.749 & $-0.130^{*}$ & 0.012 \\
\hline Birth year $\leq 1952$ & & & & $t_{i}-1$ & & & $t_{i}-1$ & & \\
\hline$t_{i}+1$ & 1344 & $100.0 \%$ & 499 & 0.821 & $-0.081^{*}$ & 0.006 & 0.728 & $-0.053^{*}$ & 0.007 \\
\hline$t_{i}+2$ & 1203 & $100.0 \%$ & 485 & 0.836 & $-0.092^{*}$ & 0.008 & 0.742 & $-0.073^{*}$ & 0.008 \\
\hline$t_{i}+3$ & 1055 & $100.0 \%$ & 480 & 0.845 & $-0.106^{*}$ & 0.009 & 0.758 & $-0.092^{*}$ & 0.010 \\
\hline$t_{i}+4$ & 918 & $99.9 \%$ & 460 & 0.853 & $-0.120^{*}$ & 0.010 & 0.767 & $-0.117^{*}$ & 0.011 \\
\hline$t_{i}+5$ & 811 & $100.0 \%$ & 437 & 0.863 & $-0.147^{*}$ & 0.011 & 0.769 & $-0.125^{*}$ & 0.012 \\
\hline Birth year > 1952 & & & & $t_{i}-1$ & & & $t_{i}-1$ & & \\
\hline$t_{i}+1$ & 1203 & $100.0 \%$ & 724 & 0.905 & $-0.115^{*}$ & 0.009 & 0.806 & $-0.074^{*}$ & 0.008 \\
\hline$t_{i}+2$ & 1018 & $100.0 \%$ & 683 & 0.905 & $-0.082^{*}$ & 0.007 & 0.805 & $-0.069^{*}$ & 0.008 \\
\hline$t_{i}+3$ & 879 & $99.9 \%$ & 650 & 0.905 & $-0.067^{*}$ & 0.007 & 0.801 & $-0.057^{*}$ & 0.008 \\
\hline$t_{i}+4$ & 726 & $100.0 \%$ & 608 & 0.906 & $-0.061^{*}$ & 0.007 & 0.809 & $-0.056^{*}$ & 0.009 \\
\hline$t_{i}+5$ & 599 & $100.0 \%$ & 571 & 0.898 & $-0.086^{*}$ & 0.008 & 0.801 & $-0.077^{*}$ & 0.010 \\
\hline Cancer onset $\leq 1990$ & & & & $t_{i}-1$ & & & $t_{i}-1$ & & \\
\hline$t_{i}+1$ & 157 & $100.0 \%$ & 269 & 0.847 & $-0.103^{*}$ & 0.011 & 0.783 & $-0.093^{*}$ & 0.013 \\
\hline$t_{i}+2$ & 156 & $100.0 \%$ & 269 & 0.840 & $-0.113^{*}$ & 0.011 & 0.776 & $-0.084^{*}$ & 0.014 \\
\hline$t_{i}+3$ & 158 & $100.0 \%$ & 267 & 0.842 & $-0.070^{*}$ & 0.013 & 0.778 & $-0.059^{*}$ & 0.015 \\
\hline Cancer onset $1991-1999$ & & & & $t_{i}-1$ & & & $t_{i}-1$ & & \\
\hline$t_{i}+1$ & 810 & $100.0 \%$ & 439 & 0.850 & $-0.086^{*}$ & 0.006 & 0.752 & $-0.061^{*}$ & 0.007 \\
\hline$t_{i}+2$ & 787 & $100.0 \%$ & 440 & 0.856 & $-0.079^{*}$ & 0.007 & 0.759 & $-0.074^{*}$ & 0.008 \\
\hline$t_{i}+3$ & 757 & $100.0 \%$ & 447 & 0.855 & $-0.092 *$ & 0.008 & 0.769 & $-0.088^{*}$ & 0.009 \\
\hline Cancer onset $\geq 2000$ & & & & $t_{i}-1$ & & & $t_{i}-1$ & & \\
\hline$t_{i}+1$ & 1580 & $100.0 \%$ & 659 & 0.868 & $-0.093^{*}$ & 0.006 & 0.772 & $-0.053^{*}$ & 0.006 \\
\hline$t_{i}+2$ & 1278 & $100.0 \%$ & 618 & 0.880 & $-0.072^{*}$ & 0.006 & 0.779 & $-0.053^{*}$ & 0.007 \\
\hline$t_{i}+3$ & 1019 & $100.0 \%$ & 585 & 0.892 & $-0.066^{*}$ & 0.007 & 0.785 & $-0.050^{*}$ & 0.007 \\
\hline
\end{tabular}

Note: ATT: Average effect of the treatment on the treated. ASE: Asymptotic standard error. $*$ : significant at $5 \%$. $\dagger$ : significant at $10 \%$. 
TABLE 3. Effect of a breast cancer (C50), socioeconomic conditioning. Difference-indifferences with dynamic matching estimates. Matching variables: lagged outcome dummies (employment, unemployment, disease), year of birth (exact), first job relative income class ( $r$, 4 levels), past disease class (3 levels), past unemployment class ( $c, 3$ levels).

\begin{tabular}{|c|c|c|c|c|c|c|c|c|c|}
\hline \multirow{2}{*}{$\begin{array}{l}\text { Time } \\
\text { after } \\
\text { event }\end{array}$} & \multirow[b]{2}{*}{ Treated } & \multirow[b]{2}{*}{ Matched } & \multirow[b]{2}{*}{ \# twins } & \multicolumn{3}{|c|}{ Employment } & \multicolumn{3}{|c|}{ Without unemployment } \\
\hline & & & & $\begin{array}{l}\text { Treated } \\
\text { lagged }\end{array}$ & ATT & ASE & $\begin{array}{l}\text { Treated } \\
\text { lagged }\end{array}$ & ATT & ASE \\
\hline$r \leq \mathrm{Q}_{1}$ & & & & $t_{i}-1$ & & & $t_{i}-1$ & & \\
\hline$t_{i}+1$ & 615 & $100.0 \%$ & 563 & 0.795 & $-0.152^{*}$ & 0.012 & 0.676 & $-0.101^{*}$ & 0.013 \\
\hline$t_{i}+2$ & 534 & $100.0 \%$ & 533 & 0.799 & $-0.132^{*}$ & 0.013 & 0.677 & $-0.107^{*}$ & 0.013 \\
\hline$t_{i}+3$ & 465 & $100.0 \%$ & 513 & 0.804 & $-0.137^{*}$ & 0.014 & 0.685 & $-0.126^{*}$ & 0.015 \\
\hline$t_{i}+4$ & 381 & $100.0 \%$ & 488 & 0.811 & $-0.122^{*}$ & 0.015 & 0.690 & $-0.110^{*}$ & 0.016 \\
\hline$t_{i}+5$ & 330 & $100.0 \%$ & 459 & 0821 & $-0.176^{*}$ & 0.017 & 0.694 & $-0.165^{*}$ & 0.018 \\
\hline $\mathrm{Q}_{1}<r \leq \mathrm{Me}$ & & & & $t_{i}-1$ & & & $t_{i}-1$ & & \\
\hline$t_{i}+1$ & 499 & $100.0 \%$ & 509 & 0.840 & $-0.119^{*}$ & 0.010 & 0.697 & $-0.071^{*}$ & 0.011 \\
\hline$t_{i}+2$ & 440 & $100.0 \%$ & 479 & 0.848 & $-0.097^{*}$ & 0.011 & 0.702 & $-0.075^{*}$ & 0.013 \\
\hline$t_{i}+3$ & 377 & $100.0 \%$ & 456 & 0.859 & $-0.081^{*}$ & 0.012 & 0.713 & $-0.063^{*}$ & 0.015 \\
\hline$t_{i}+4$ & 329 & $100.0 \%$ & 412 & 0.857 & $-0.079^{*}$ & 0.014 & 0.705 & $-0.067^{*}$ & 0016 \\
\hline$t_{i}+5$ & 289 & $100.0 \%$ & 381 & 0.848 & $-0.083^{*}$ & 0.014 & 0.685 & $-0.077^{*}$ & 0.017 \\
\hline $\mathrm{Me}<r \leq \mathrm{Q}_{3}$ & & & & $t_{i}-1$ & & & $t_{i}-1$ & & \\
\hline$t_{i}+1$ & 649 & $100.0 \%$ & 653 & 0.892 & $-0.093^{*}$ & 0.010 & 0.807 & $-0.060^{*}$ & 0.010 \\
\hline$t_{i}+2$ & 567 & $100.0 \%$ & 621 & 0.899 & $-0.082^{*}$ & 0.010 & 0.811 & $-0.060^{*}$ & 0.011 \\
\hline$t_{i}+3$ & 488 & $100.0 \%$ & 600 & 0.902 & $-0.081^{*}$ & 0.011 & 0.807 & $-0.066^{*}$ & 0.012 \\
\hline$t_{i}+4$ & 406 & $99.8 \%$ & 558 & 0.901 & $-0.082^{*}$ & 0.013 & 0.820 & $-0.089 *$ & 0.014 \\
\hline$t_{i}+5$ & 341 & $100.0 \%$ & 517 & 0.903 & $-0.103^{*}$ & 0.013 & 0.827 & $-0.084^{*}$ & 0.015 \\
\hline$r>\mathrm{Q}_{3}$ & & & & $t_{i}-1$ & & & $t_{i}-1$ & & \\
\hline$t_{i}+1$ & 784 & $100.0 \%$ & 660 & 0.899 & $-0.047^{*}$ & 0.007 & 0.843 & $-0.031^{*}$ & 0.008 \\
\hline$t_{i}+2$ & 680 & $100.0 \%$ & 635 & 0.907 & $-0.051^{*}$ & 0.008 & 0.854 & $-0.049^{*}$ & 0.010 \\
\hline$t_{i}+3$ & 604 & $100.0 \%$ & 620 & 0.911 & $-0.061^{*}$ & 0.010 & 0.864 & $-0.054^{*}$ & 0.011 \\
\hline$t_{i}+4$ & 528 & $100.0 \%$ & 598 & 0.917 & $-0.092^{*}$ & 0.011 & 0.877 & $-0.090^{*}$ & 0.013 \\
\hline$t_{i}+5$ & 450 & $100.0 \%$ & 574 & 0.920 & $-0.119^{*}$ & 0.014 & 0.878 & $-0.095^{*}$ & 0.015 \\
\hline$c=0$ & & & & $t_{i}-1$ & & & $t_{i}-1$ & & \\
\hline$t_{i}+1$ & 1217 & $100.0 \%$ & 351 & 0.917 & $-0.054^{*}$ & 0.007 & 0.917 & $-0.047^{*}$ & 0.008 \\
\hline$t_{i}+2$ & 1082 & $100.0 \%$ & 352 & 0.920 & $-0.057^{*}$ & 0.008 & 0.920 & $-0.063^{*}$ & 0.009 \\
\hline$t_{i}+3$ & 967 & $100.0 \%$ & 352 & 0.918 & $-0.080^{*}$ & 0.009 & 0.918 & $-0.077^{*}$ & 0.010 \\
\hline$t_{i}+4$ & 848 & $99.9 \%$ & 348 & 0.920 & $-0.089^{*}$ & 0.010 & 0.920 & $-0.099^{*}$ & 0.011 \\
\hline$t_{i}+5$ & 739 & $100.0 \%$ & 342 & 0.924 & $-0.120^{*}$ & 0.012 & 0.924 & $-0.110^{*}$ & 0.012 \\
\hline $0<c \leq 0.16$ & & & & $t_{i}-1$ & & & $t_{i}-1$ & & \\
\hline$t_{i}+1$ & 743 & $100.0 \%$ & 163 & 0.846 & $-0.114^{*}$ & 0.008 & 0.704 & $-0.077^{*}$ & 0.009 \\
\hline$t_{i}+2$ & 634 & $100.0 \%$ & 149 & 0.853 & $-0.102^{*}$ & 0.009 & 0.710 & $-0.079^{*}$ & 0.010 \\
\hline$t_{i}+3$ & 533 & $100.0 \%$ & 142 & 0.862 & $-0.099^{*}$ & 0.010 & 0.720 & $-0.096^{*}$ & 0.011 \\
\hline$t_{i}+4$ & 446 & $100.0 \%$ & 130 & 0.871 & $-0.109^{*}$ & 0.010 & 0.727 & $-0.109 *$ & 0.012 \\
\hline$t_{i}+5$ & 367 & $100.0 \%$ & 114 & 0.874 & $-0.125^{*}$ & 0.011 & 0.717 & $-0.111^{*}$ & 0.012 \\
\hline$c>0.16$ & & & & $t_{i}-1$ & & & $t_{i}-1$ & & \\
\hline$t_{i}+1$ & 587 & $100.0 \%$ & 283 & 0.764 & $-0.166^{*}$ & 0.012 & 0.533 & $-0.079^{*}$ & 0.012 \\
\hline$t_{i}+2$ & 505 & $100.0 \%$ & 261 & 0.777 & $-0.127^{*}$ & 0.012 & 0.531 & $-0.082^{*}$ & 0.013 \\
\hline$t_{i}+3$ & 434 & $100.0 \%$ & 247 & 0.789 & $-0.093^{*}$ & 0.011 & 0.539 & $-0.053^{*}$ & 0.014 \\
\hline$t_{i}+4$ & 350 & $100.0 \%$ & 229 & 0.787 & $-0.083^{*}$ & 0.013 & 0.543 & $-0.043^{*}$ & 0.015 \\
\hline$t_{i}+5$ & 304 & $100.0 \%$ & 215 & 0.781 & $-0.119^{*}$ & 0.013 & 0.530 & $-0.087^{*}$ & 0.016 \\
\hline
\end{tabular}

Note: ATT: Average effect of the treatment on the treated. ASE: Asymptotic standard error. $*$ : significant at $5 \%$. $\dagger$ : significant at $10 \%$. 


\section{A Estimation of the standard errors}

This section presents the computation of the standard errors without using bootstrapping, to save computing time. The ATT estimator, denoted $\hat{c}$, can be written as follows:

$$
\hat{c}=\frac{1}{I} \sum_{i \in I} \hat{c}_{i} \text { with } \hat{c}_{i}=\Delta y_{i}-\frac{1}{J(i)} \sum_{j \in J(i)} \Delta y_{j}
$$

where $I$ is the treated set (and their number), $y_{i}$ is the outcome variable of individual $i, \Delta y_{i}$ is the before-after difference and $J(i)$ is the set of individual $i$ 's twins (and their number). The previous formula defines the DiD estimator. If two treated individuals have the same matching variables, and if their treatment occurs on the same date, they will be matched with exactly the same twins, and hence the same mean will be subtracted from their outcome variable. We regroup the treated according to their matching variables and treatment date. Let $k \in K$ be a specific vector regrouping the matching variables and the treatment date; the set of all the treated individuals in the matching group $k$ (and their number) is defined by

$$
I(k)=\left\{i \in I:\left(X_{i}, t_{i}\right)=k\right\}, k \in K
$$

and we let $J(k)$ denote the common matching twins' set of the treated in group $k$ (and their number). By definition, the $I(k)$ sets define a partition of the treated set $I=\bigcap_{k} I(k), I(k) \cap I\left(k^{\prime}\right)=$ $\varnothing \forall k \neq k^{\prime}$. Therefore, the ATT can be rewritten as follows:

$$
\hat{c}=\frac{1}{I} \sum_{k \in K} \sum_{i \in I(k)}\left(\Delta y_{i}-m_{k}\right)
$$

where $m_{k}=J(k)^{-1} \sum_{j \in J(k)} \Delta y_{j}$ is the matching twins' common mean within group $k$. Simplifying within the sum, we obtain

$$
\hat{c}=\frac{1}{I} \sum_{k \in K}\left\{\sum_{i \in I(k)} \Delta y_{i}-I(k) m_{k}\right\}
$$

To compute the variance of this estimator, we make the standard independence assumption between the $y_{i}$ 's. First, the groups $k$ are independent of one another because they have neither a treated nor a twin in common. We obtain

$$
\mathrm{V}(\hat{c})=\frac{1}{I^{2}} \sum_{k \in K} \mathrm{~V}\left(\sum_{i \in I(k)} \Delta y_{i}-I(k) m_{k}\right)
$$

Second, the $y_{i}$ 's are independent of the $m_{k}$ 's because they are computed from different individuals. We obtain

$$
\begin{aligned}
\mathrm{V}(\hat{c}) & =\frac{1}{I^{2}} \sum_{k \in K}\left\{\mathrm{~V}\left(\sum_{i \in I(k)} \Delta y_{i}\right)+I(k)^{2} \mathrm{~V}\left(m_{k}\right)\right\} \\
& =\sum_{k \in K}\left(\frac{I(k)}{I}\right)^{2}\left\{\mathrm{~V}\left(m_{k}^{T}\right)+\mathrm{V}\left(m_{k}\right)\right\}
\end{aligned}
$$

with $m_{k}^{T}=I(k)^{-1} \sum_{i \in I(k)} \Delta y_{i}$ the mean outcome of the treated within group $k$. The estimator is obtained by replacing the theoretical statistics with their empirical counterparts. 
TABLE 4. Effect of a breast cancer, complementary variables (C50), time-related conditioning. Difference-in-differences with dynamic matching estimates. Matching variables: lagged outcome dummies (employment, unemployment, disease), year of birth (exact), first job relative income class ( $r, 4$ levels), past disease class (3 levels), past unemployment class ( $c, 3$ levels).

\begin{tabular}{|c|c|c|c|c|c|c|c|c|c|}
\hline \multirow{2}{*}{$\begin{array}{l}\text { Time } \\
\text { after } \\
\text { event }\end{array}$} & \multirow[b]{2}{*}{ Treated } & \multirow[b]{2}{*}{ Matched } & \multirow[b]{2}{*}{ \# twins } & \multicolumn{3}{|c|}{ Disease } & \multicolumn{3}{|c|}{ Unemployment } \\
\hline & & & & $\begin{array}{l}\text { Treated } \\
\text { lagged }\end{array}$ & ATT & ASE & $\begin{array}{l}\text { Treated } \\
\text { lagged }\end{array}$ & ATT & ASE \\
\hline Full sample & & & & $t_{i}-1$ & & & $t_{i}-1$ & & \\
\hline$t_{i}+1$ & 2547 & $100.0 \%$ & 605 & 0.056 & $0.528^{*}$ & 0.007 & 0.163 & $-0.037^{*}$ & 0.004 \\
\hline$t_{i}+2$ & 2221 & $100.0 \%$ & 576 & 0.057 & $0.274^{*}$ & 0.007 & 0.160 & -0.007 & 0.005 \\
\hline$t_{i}+3$ & 1934 & $100.0 \%$ & 557 & 0.058 & $0.147^{*}$ & 0.007 & 0.152 & 0.007 & 0.006 \\
\hline$t_{i}+4$ & 1644 & $99.9 \%$ & 526 & 0.058 & $0.047^{*}$ & 0.005 & 0.143 & $0.015^{*}$ & 0.006 \\
\hline$t_{i}+5$ & 1410 & $100.0 \%$ & 494 & 0.059 & $0.049^{*}$ & 0.006 & 0.144 & $0.012^{\dagger}$ & 0.007 \\
\hline Age at cancer $\leq 48$ & & & & $t_{i}-1$ & & & $t_{i}-1$ & & \\
\hline$t_{i}+1$ & 1310 & $100.0 \%$ & 684 & 0.072 & $0.548^{*}$ & 0.009 & 0.140 & $-0.032^{*}$ & 0.005 \\
\hline$t_{i}+2$ & 1185 & $100.0 \%$ & 644 & 0.070 & $0.268^{*}$ & 0.009 & 0.138 & 0.006 & 0.006 \\
\hline$t_{i}+3$ & 1100 & $100.0 \%$ & 617 & 0.072 & $0.140^{*}$ & 0.008 & 0.139 & $0.017^{*}$ & 0.006 \\
\hline$t_{i}+4$ & 986 & $100.0 \%$ & 583 & 0.070 & $0.050^{*}$ & 0.006 & 0.131 & $0.019^{*}$ & 0.007 \\
\hline$t_{i}+5$ & 892 & $100.0 \%$ & 555 & 0.070 & $0.056^{*}$ & 0.007 & 0.132 & 0.003 & 0.007 \\
\hline Age at cancer $>48$ & & & & $t_{i}-1$ & & & $t_{i}-1$ & & \\
\hline$t_{i}+1$ & 1237 & $100.0 \%$ & 514 & 0.039 & $0.486^{*}$ & 0.009 & 0.188 & $-0.042^{*}$ & 0.005 \\
\hline$t_{i}+2$ & 1036 & $100.0 \%$ & 486 & 0.039 & $0.256^{*}$ & 0.009 & 0.188 & $-0.025^{*}$ & 0.007 \\
\hline$t_{i}+3$ & 834 & $100.0 \%$ & 464 & 0.042 & $0.123^{*}$ & 0.009 & 0.186 & -0.010 & 0.009 \\
\hline$t_{i}+4$ & 658 & $100.0 \%$ & 432 & 0.040 & 0.007 & 0.007 & 0.168 & 0.005 & 0.010 \\
\hline$t_{i}+5$ & 518 & $100.0 \%$ & 390 & 0.039 & -0.005 & 0.007 & 0.162 & $0.023^{\dagger}$ & 0.012 \\
\hline Birth year $\leq 1952$ & & & & $t_{i}-1$ & & & $t_{i}-1$ & & \\
\hline$t_{i}+1$ & 1344 & $100.0 \%$ & 499 & 0.044 & $0.469^{*}$ & 0.010 & 0.184 & $-0.033^{*}$ & 0.005 \\
\hline$t_{i}+2$ & 1203 & $100.0 \%$ & 485 & 0.044 & $0.254^{*}$ & 0.010 & 0.173 & -0.010 & 0.007 \\
\hline$t_{i}+3$ & 1055 & $100.0 \%$ & 480 & 0.046 & $0.133^{*}$ & 0.009 & 0155 & 0.008 & 0.009 \\
\hline$t_{i}+4$ & 918 & $99.9 \%$ & 460 & 0.046 & $0.037^{*}$ & 0.007 & 0.146 & $0.019^{\dagger}$ & 0.010 \\
\hline$t_{i}+5$ & 811 & $100.0 \%$ & 437 & 0.047 & $0.034^{*}$ & 0.008 & 0.147 & $0.020^{*}$ & 0.010 \\
\hline Birth year > 1952 & & & & $t_{i}-1$ & & & $t_{i}-1$ & & \\
\hline$t_{i}+1$ & 1203 & $100.0 \%$ & 724 & 0.070 & $0.594^{*}$ & 0.010 & 0.140 & $-0.041^{*}$ & 0.005 \\
\hline$t_{i}+2$ & 1018 & $100.0 \%$ & 683 & 0.073 & $0.298^{*}$ & 0.010 & 0.145 & -0.002 & 0.007 \\
\hline$t_{i}+3$ & 879 & $99.9 \%$ & 650 & 0.073 & $0.163^{*}$ & 0.010 & 0.148 & 0.005 & 0.007 \\
\hline$t_{i}+4$ & 726 & $100.0 \%$ & 608 & 0.074 & $0.060^{*}$ & 0.007 & 0.139 & 0.011 & 0.008 \\
\hline$t_{i}+5$ & 599 & $100.0 \%$ & 571 & 0.075 & $0.070^{*}$ & 0.008 & 0.140 & 0.000 & 0.008 \\
\hline Cancer onset $\leq 1990$ & & & & $t_{i}-1$ & & & $t_{i}-1$ & & \\
\hline$t_{i}+1$ & 157 & $100.00 \%$ & 269 & 0.076 & $0.381^{*}$ & 0.022 & 0.096 & $0.024^{*}$ & 0.008 \\
\hline$t_{i}+2$ & 156 & $100.00 \%$ & 269 & 0.071 & $0.170^{*}$ & 0.019 & 0.096 & 0.015 & 0.011 \\
\hline$t_{i}+3$ & 158 & $100.00 \%$ & 267 & 0.076 & $0.127^{*}$ & 0.018 & 0.095 & -0.007 & 0.009 \\
\hline Cancer onset $1991-1999$ & & & & $t_{i}-1$ & & & $t_{i}-1$ & & \\
\hline$t_{i}+1$ & 810 & $100.00 \%$ & 439 & $\begin{array}{lll}l & 1 \\
0.048 & 0\end{array}$ & $0.466^{*}$ & 0.010 & 0.159 & $-0.034^{*}$ & 0.006 \\
\hline$t_{i}+2$ & 787 & $100.00 \%$ & 440 & 0.047 & $0.235^{*}$ & 0.010 & 0.157 & 0.007 & 0.008 \\
\hline$t_{i}+3$ & 757 & $100.00 \%$ & 447 & 0.048 & $0.131^{*}$ & 0.009 & 0.141 & $0.030^{*}$ & 0.008 \\
\hline Cancer onset $\geq 2000$ & & & & $t_{i}-1$ & & & $t_{i}-1$ & & \\
\hline$t_{i}+1$ & 1580 & $100.00 \%$ & 659 & 0.057 & $0.559^{*}$ & 0.008 & 0.171 & $-0.046^{*}$ & 0.004 \\
\hline$t_{i}+2$ & 1278 & $100.00 \%$ & 618 & 0.061 & $0.292^{*}$ & 0.009 & 0.170 & $-0.022^{*}$ & 0.006 \\
\hline$t_{i}+3$ & 1019 & $100.00 \%$ & 585 & 0.061 & $0.137^{*}$ & 0.008 & 0.168 & $-0.014^{*}$ & 0.006 \\
\hline
\end{tabular}

Note: ATT: Average effect of the treatment on the treated. ASE: Asymptotic standard error. $*$ : significant at $5 \%$. $\dagger$ : significant at $10 \%$. 
TABLE 5. Effect of a breast cancer (C50), complementary variables, socioeconomic conditioning. Difference-in-differences with dynamic matching estimates. Matching variables: lagged outcome dummies (employment, unemployment, disease), year of birth (exact), first job relative income class ( $r, 4$ levels), past disease class (3 levels), past unemployment class ( $c$, 3 levels).

\begin{tabular}{|c|c|c|c|c|c|c|c|c|c|}
\hline \multirow{2}{*}{$\begin{array}{l}\text { Time } \\
\text { after } \\
\text { event }\end{array}$} & \multirow[b]{2}{*}{ Treated } & \multirow[b]{2}{*}{ Matched } & \multirow[b]{2}{*}{ \# twins } & \multicolumn{3}{|c|}{ Disease } & \multicolumn{3}{|c|}{ Unemployment } \\
\hline & & & & $\begin{array}{l}\text { Treated } \\
\text { lagged }\end{array}$ & ATT & ASE & $\begin{array}{l}\text { Treated } \\
\text { lagged }\end{array}$ & ATT & ASE \\
\hline$r \leq \mathrm{Q}_{1}$ & & & & $t_{i}-1$ & & & $t_{i}-1$ & & \\
\hline$t_{i}+1$ & 615 & $100.0 \%$ & 563 & 0.039 & $0.510^{*}$ & 0.014 & 0.208 & $-0.048^{*}$ & 0.010 \\
\hline$t_{i}+2$ & 534 & $100.0 \%$ & 533 & 0.039 & $0.295^{*}$ & 0.014 & 0.212 & -0.013 & 0.011 \\
\hline$t_{i}+3$ & 465 & $100.0 \%$ & 513 & 0.039 & $0.151^{*}$ & 0.013 & 0.192 & 0.017 & 0.013 \\
\hline$t_{i}+4$ & 381 & $100.0 \%$ & 488 & 0.037 & $0.044^{*}$ & 0.010 & 0.189 & 0.011 & 0.014 \\
\hline$t_{i}+5$ & 330 & $100.0 \%$ & 459 & 0.030 & $0.029^{*}$ & 0.010 & 0.185 & $0.043^{*}$ & 0.015 \\
\hline $\mathrm{Q}_{1}<r \leq \mathrm{Me}$ & & & & $t_{i}-1$ & & & $t_{i}-1$ & & \\
\hline$t_{i}+1$ & 499 & $100.0 \%$ & 509 & 0.074 & $0.486^{*}$ & 0.015 & 0.214 & $-0.043^{*}$ & 0.008 \\
\hline$t_{i}+2$ & 440 & $100.0 \%$ & 479 & 0.073 & $0.215^{*}$ & 0.014 & 0.209 & 0002 & 0.011 \\
\hline$t_{i}+3$ & 377 & $100.0 \%$ & 456 & 0.074 & $0.122^{*}$ & 0.013 & 0.202 & 0.016 & 0.014 \\
\hline$t_{i}+4$ & 329 & $100.0 \%$ & 412 & 0.076 & $0.035^{*}$ & 0.011 & 0.210 & $0.029 *$ & 0.014 \\
\hline$t_{i}+5$ & 289 & $100.0 \%$ & 381 & 0.076 & $0.060^{*}$ & 0.011 & 0.221 & 0.009 & 0.014 \\
\hline $\mathrm{Me}<r \leq \mathrm{Q}_{3}$ & & & & $t_{i}-1$ & & & $t_{i}-1$ & & \\
\hline$t_{i}+1$ & 649 & $100.0 \%$ & 653 & 0.052 & 0588* & 0.014 & 0134 & $-0.039^{*}$ & 0.007 \\
\hline$t_{i}+2$ & 567 & $100.0 \%$ & 621 & 0.060 & $0.323^{*}$ & 0.015 & 0.136 & -0.013 & 0.009 \\
\hline$t_{i}+3$ & 488 & $100.0 \%$ & 600 & 0.061 & $0.172^{*}$ & 0.014 & 0.139 & 0.012 & 0.011 \\
\hline$t_{i}+4$ & 406 & $99.8 \%$ & 558 & 0.064 & $0.045^{*}$ & 0.010 & 0.123 & $0.025^{*}$ & 0.012 \\
\hline$t_{i}+5$ & 341 & $100.0 \%$ & 517 & 0.067 & $0.046^{*}$ & 0.011 & 0.120 & 0.004 & 0.013 \\
\hline$r>\mathrm{Q}_{3}$ & & & & $t_{i}-1$ & & & $t_{i}-1$ & & \\
\hline$t_{i}+1$ & 784 & $1000 \%$ & 660 & 0.061 & $0.518^{*}$ & 0.014 & 0.120 & $-0.023^{*}$ & 0.006 \\
\hline$t_{i}+2$ & 680 & $100.0 \%$ & 635 & 0.059 & $0.256^{*}$ & 0.014 & 0.109 & -0.002 & 0.009 \\
\hline$t_{i}+3$ & 604 & $100.0 \%$ & 620 & 0.060 & $0.139 *$ & 0.012 & 0.099 & -0.011 & 0.009 \\
\hline$t_{i}+4$ & 528 & $100.0 \%$ & 598 & 0.059 & $0.058^{*}$ & 0.010 & 0.083 & 0.003 & 0.011 \\
\hline$t_{i}+5$ & 450 & $100.0 \%$ & 574 & 0.062 & $0.059^{*}$ & 0.012 & 0.082 & -0.004 & 0.013 \\
\hline$c=0$ & & & & $t_{i}-1$ & & & $t_{i}-1$ & & \\
\hline$t_{i}+1$ & 1217 & $100.0 \%$ & 351 & 0.044 & $0.526^{*}$ & 0.012 & 0.000 & -0.008 & 0.005 \\
\hline$t_{i}+2$ & 1082 & $100.0 \%$ & 352 & 0.047 & $0.277^{*}$ & 0.012 & 0.000 & $0.015^{*}$ & 0.007 \\
\hline$t_{i}+3$ & 967 & $100.0 \%$ & 352 & 0.050 & $0.143^{*}$ & 0.011 & 0.000 & $0.022^{*}$ & 0.008 \\
\hline$t_{i}+4$ & 848 & $99.9 \%$ & 348 & 0.050 & $0.051^{*}$ & 0.008 & 0.000 & $0.035^{*}$ & 0.010 \\
\hline$t_{i}+5$ & 739 & $100.0 \%$ & 342 & 0.050 & $0.056^{*}$ & 0.009 & 0.000 & $0.035^{*}$ & 0.010 \\
\hline $0<c \leq 0.16$ & & & & $t_{i}-1$ & & & $t_{i}-1$ & & \\
\hline$t_{i}+1$ & 743 & $100.0 \%$ & 163 & 0.057 & $0.514^{*}$ & 0.011 & 0.239 & $-0.034^{*}$ & 0.007 \\
\hline$t_{i}+2$ & 634 & $100.0 \%$ & 149 & 0.055 & $0.249^{*}$ & 0.010 & 0.230 & -0.013 & 0.008 \\
\hline$t_{i}+3$ & 533 & $100.0 \%$ & 142 & 0.051 & $0.135^{*}$ & 0.010 & 0.214 & 0.007 & 0.010 \\
\hline$t_{i}+4$ & 446 & $100.0 \%$ & 130 & 0.050 & $0.031^{*}$ & 0.008 & 0.205 & $0.019^{\dagger}$ & 0.011 \\
\hline$t_{i}+5$ & 367 & $100.0 \%$ & 114 & 0.052 & $0.035^{*}$ & 0.008 & 0.206 & 0.009 & 0.011 \\
\hline$c>0.16$ & & & & $t_{i}-1$ & & & $t_{i}-1$ & & \\
\hline$t_{i}+1$ & 587 & $100.0 \%$ & 283 & 0.075 & $0.551^{*}$ & 0.013 & 0.406 & $-0.099^{*}$ & 0.010 \\
\hline$t_{i}+2$ & 505 & $100.0 \%$ & 261 & 0.074 & $0.307^{*}$ & 0.014 & 0.417 & $-0.044^{*}$ & 0.013 \\
\hline$t_{i}+3$ & 434 & $100.0 \%$ & 247 & 0.076 & $0.170^{*}$ & 0.013 & 0.414 & $-0.030^{*}$ & 0.014 \\
\hline$t_{i}+4$ & 350 & $100.0 \%$ & 229 & 0.080 & $0.056^{*}$ & 0.010 & 0.408 & $-0.037^{*}$ & 0.014 \\
\hline$t_{i}+5$ & 304 & $100.0 \%$ & 215 & 0.076 & $0.047^{*}$ & 0.010 & 0.417 & $-0.044^{*}$ & 0.015 \\
\hline
\end{tabular}

Note: ATT: Average effect of the treatment on the treated. ASE: Asymptotic standard error. $*$ : significant at $5 \%$. $\dagger$ : significant at $10 \%$. 


\section{References}

[1] Barnay, T., M. A. Ben Halima, E. Duguet, J. Lanfranchi, and C. Le Clainche (2015), "La survenue du cancer : effets de court et moyen termes sur les situations professionnelles". Economie et Statistique, 475-476, 157-186.

[2] Blinder, V. S., S. Patil, A. Thind, A. Diamant, C. A. Hudis, E. Basch, and R. C. Maly (2012), "Return to work in low-income Latina and non-Latina white breast cancer survivors: A 3-year longitudinal study”. Cancer, 118 (6), 1664-1674.

[3] Bradley C. J., Bednarek H. L. et Neumark D. (2002), "Breast cancer survival, work, and earnings". Journal of Health Economics, vol. 21, n 5, pp. 757-779.

[4] Bradley, C. J., D. Neumark, and S. Barkowski (2013), "Does employer-provided health insurance constrain labor supply adjustments to health shocks? New evidence on women diagnosed with breast cancer". Journal of Health Economics, 32 (5), 833-849.

[5] Bradley, C., D. Neumark, H. L. Bednarek, and M. Schenk (2004), "Short-term effects of breast cancer on labor market attachment : Results from a longitudinal study". Journal of Health Economics, 24, 137-160.

[6] Bradley, C. J., D. Neumark, Z. Luo, and H. L. Bednarek (2007), "Employment-contingent health insurance, illness, and labor supply of women: Evidence from married women with breast cancer". Health Economics, 16 (7), 719-737.

[7] Bradley, C. J., K. Oberst, and M. Schenk (2006), "Absenteeism from work: The experience of employed breast and prostate cancer patients in the months following diagnosis". Psychooncology, 15 (8), 739-747.

[8] Carlsen, K., J. H. Badsberg, and S. Dalton (2014), "Unemployment among breast cancer survivors”. Scandinavian Journal of Public Health, 42(3):319-28.

[9] Carlsen K, Oksbjerg DS, Frederiksen K, Diderichsen F, Johansen C (2008), "Cancer and the risk for taking early retirement pension: a Danish cohort study". Scandinavian Journal of Public Health, 36: 117-125.

[10] Chirikos, T. N., A. Russell-Jacobs, and A. B. Cantor (2002), "Indirect economic effects of long term breast cancer survival”. Cancer Practice, 10 (5), 248-255.

[11] Chirikos, T. N., A. Russell-Jacobs, and P. B. Jacobsen (2002), "Functional impairment and the economic consequences of female breast cancer". Women and Health, 36 (1), 1-20.

[12] Cutler, D. M. (2008), "Are we finally winning the war on cancer?" Journal of Economic Perspectives, 22 (4), 3-26.

[13] Damkjaer, L. H., I. Deltour, N. P. Suppli, J. Christensen, N. T. Kroman, C. Johansen, and S. O. Dalton (2011), "Breast cancer and early retirement: Associations with disease characteristics, treatment, comorbidity, social position and participation in a six-day rehabilitation course in a register-based study in Denmark". Acta Oncologica, 50 (2), 274-281.

[14] Datta Gupta N. et Larsen M. (2010), "The impact of health on individual retirement plans: Self-reported versus diagnostic measures ”. Health Economics, vol. 19, nº 7, pp. 792-813. 
[15] De Boer, A. G., T. Taskila, A. Ojajarvi, F. J. van Dijk, and J. H. Verbeek (2009), "Cancer survivors and unemployment : a meta-analysis and meta regression”. JAMA, 301 (7), 753-762.

[16] Drolet, M., E. Maunsell, M. Mondor, C. Brisson, J. Brisson, B. Masse, and L. Deschenes (2005), "Work absence after breast cancer diagnosis: A population-based study". Canadian Medical Association Journal, 173 (7), 765-771.

[17] Duguet, E. and C. Le Clainche (2016), “Une évaluation de l'impact de l'aménagement des conditions de travail sur la reprise du travail après un cancer". Revue Economique, 71 (1), 49-79.

[18] Eichenbaum-Voline, S., L. Malavolti, A. Paraponaris, and B. Ventelou (2008), "Cancer et activité professionnelle". La Revue de l'OFCE, 104, 105-134.

[19] Eunmi, A., J. Cho, D. W. Shin, B. W. Park, S. H. Ahn, D. Y. Noh, S. J. Nam, E. S. Lee, and Y. H. Yun (2009), "Impact of breast cancer diagnosis and treatment on work-related life and factors affecting them”. Breast Cancer Research and Treatment, 116 (3), 609-616.

[20] Farley, P., J. Vasey, and J. Moran (2008), "Long-term effects of cancer survivorship on the employment of older workers”. Health Services Research, 43 (1), 193-210.

[21] Feuerstein, M., B. L. Todd, M. C. Moskowitz, G. L. Bruns, M. R. Stoler, T. Nassif, and X. Yu (2010), "Work in cancer survivors: A model for practice and research". Journal of Cancer Survivorship, Research and Practice, 4, 415-437.

[22] Gregg, P. and E. Tominey (2005), “The wage scar from youth unemployment”. The Centre for Market and Public Organisation Working Paper Series No. 04/097, Department of Economics, University of Bristol, UK.

[23] Grossman, M. (1972), "On the concept of health capital and the demand for health". Journal of Political Economy, 80 (2), 223-255.

[24] Hassett, M., J. O’Malley, and N. Keating (2009), "Factors influencing changes in employment among women with newly diagnosed breast cancer”. American Cancer Society, 115, $2775-2782$.

[25] Heckman, J. J. and G. Borjas (1980), "Does unemployment cause future unemployment? Definitions, questions and answers from a continuous time model of heterogeneity and state dependence". Economica, 47, 247-283.

[26] Heckman, J. J., H. Ichimura, and P. E. Todd (1997), "Matching as an econometric evaluation estimator: Evidence from evaluating a job training programme". Review of Economic Studies, 64 (4), 605-654.

[27] Heinesen, E. and C. Kolodziejczyk (2013), "Effects of breast and colorectal cancer on labour market outcomes-average effects and educational gradients." Journal of Health Economics, 32, 1028-1042.

[28] INCA (2014). Annual report, French Cancer Institute.

[29] INCA (2015). Annual report, French Cancer Institute. 
[30] Jagsi, R., S. Hawley, P. Abrahamse, Y. Li, N. Janz, J. Griggs, C. Bradley, J. Graff, A. Hamilton, and S. Kratz (2014), "Impact of adjuvant chemotherapy on long-term employment of survivors of early-stage breast cancer”. Cancer, 120 (12), 1854-1862.

[31] Johnsson, A., T. Fornander, L. E. Rutqvist, and M. Olsson (2011), "WWork status and life changes in the first year after breast cancer diagnosis”. Work, 38, 337-346.

[32] Jooste, V., P. Grosclaude, L. Remontet, G. Launoy, I. Baldi, F. Molinie, P. Arveux, N. Bossard, A. M. Bouvier, and M. Colonna (2013), "Unbiased estimates of long-term net survival of solid cancers in France”. International Journal of Cancer, 132 (10), 2370-2377.

[33] Joutard, X., A. Paraponaris, L. Sagaon-Teyssier, and B. Ventelou (2012), "A continuous-time Markov model for transitions between employment and non-employment: the impact of a cancer diagnosis." Annals of Economics and Statistics, 107-108, 239-266.

[34] Lee M.-J. (2003). Micro-Econometrics for Policy, Program and Treatment Effects. Oxford University Press. ISBN 978-0-19-926769-9.

[35] Lindbohm, M. L., E. Kuosma, T. Taskila, P. Hietanen, K. Carlsen, S. Gudbergsson, and H. Gunnarsdottir (2011), "Cancer as the cause of changes in work situation". Psychooncology, 20, 805-812.

[36] Marino, P., T. L. Sagaon, M. Laetitia, and L. C. S. Anne-Gaelle (2013), "Sex differences in the return-to-work process of cancer survivors 2 years after diagnosis: results from a large French population-based sample". Journal of Clinical Oncology, 31, 1-10.

[37] Mehnert, A. (2011), "Employment and work-related issues in cancer survivors". Critical Reviews in Oncology Hematology, 77, 109-130.

[38] Moran, J. R., P. F. Short, and C. S. Hollenbeak (2011), "Long-term Employment effects of Surviving Cancer”. Journal of Health Economics, 30 (3), 505-514.

[39] Mujahid, M. S., N. K. Janz, S. T. Hawley, J. J. Griggs, A. S. Hamilton, J. Graff, and S. J. Katz (2011), "Racial/ethnic differences in job loss for women with breast cancer". Journal of Cancer Survivorship, Research and Practice, 5, 102-111.

[40] Oberst, K., C. J. Bradley, J. C. Gardiner, M. Schenk, and C. W. Given (2010), “Work task disability in employed breast and prostate cancer patients". Journal of Cancer Survivorship, Research and Practice, 4 (4), 322-330.

[41] Observatoire Sociétal des Cancers, 2014. Cancer du Sein : se reconstruire après une mastectomie. Annual report 2014.

[42] Paraponaris, A., L. S. Teyssier, and B. Ventelou (2010), "Job tenure and self-reported workplace discrimination for cancer survivors 2 years after diagnosis: Does employment legislation matter?" Health Policy, 98, 144-155.

[43] Petersson LM, Wennman-Larsen A, Nilsson M, Olsson M, Alexanderson K. (2011), "Work situation and sickness absence in the initial period after breast cancer surgery"; Acta Oncol., 50(2):282-8.

[44] Pourquier H. (2000), "Le traitement des cancers du sein : ses progrès et ses limites". Cancer/Radiother, $4: 248-52$. 
[45] Quinlan, E., R. Thomas-MacLean, T. Hack, W. Kwan, B. Miedema, S. Tatemichi, A. Towers, and A. Tilley (2009), "The impact of breast cancer among Canadian women: Disability and productivity”. Work, 34 (3), 285-296.

[46] Taskila-Abrandt, T., E. Pukkala, R. Martikainen, A. Karjalainen, and P. Hietanen (2005), "Employment status of Finnish cancer patients in 1997". Psycho-Oncology, 14 (3), 221-226.

[47] Torp, S., S. Gudbergsson, A. Dahl, S. Fossa, and T. Fløtten (2011), "Social support at work and work changes among cancer survivors in Norway". Scandinavian Journal of Public Health, 39 (6), 33-42.

[48] Yarker, J., Munir, F., Donaldson-Feilder, E., Hicks, B., (2010). "Managing Rehabilitation: Competency Framework for Managers to Support Return to Work”. BOHRF, London. 
16-4. Expectations, Loss Aversion, and Retirement Decisions in the Context of the 2009 Crisis in Europe

Nicolas Sirven, Thomas Barnay

16-3. How do product and labor market regulations affect aggregate employment, inequalities and job polarization? A general equilibrium approach

Julien Albertini, Jean-Olivier Hairault, François Langot, Thepthida Sopraseuth

16-2. Acces to employment with age and gender: results of a controlled experiment Laetitia Challe, Florent Fremigacci, François Langot, Yannick L'Horty, Loïc Du Parquet, Pascale Petit

16-1. An evaluation of the 1987 French Disabled Workers Act: Better paying than hiring

Thomas Barnay, Emmanuel Duguet, Christine Le Clainche, Yann Videau 
15-10. Optimal Income Taxation with Unemployment and Wage Responses: A Sufficient Statistics Approach

Kory Kroft, Kavan Kucko, Etienne Lehmann, Johannes Schmieder

15-9. Search frictions and (in) efficient vocational training over the life-cycle Arnaud Chéron, Anthony Terriau

15-8. Absenteeism and productivity: the experience rating applied to employer contributions to health insurance

Sébastien Ménard, Coralia Quintero Rojas

15-7. Take up of social assistance benefits: the case of homeless

Sylvain Chareyron

15-6. Spatial mismatch through local public employment agencies. Answers from a French quasi-experiment

Mathieu Bunel, Elisabeth Tovar

15-5. Transmission of vocational skills at the end of career: horizon effect and technological or organisational change

Nathalie Greenan, Pierre-Jean Messe

15-4. Protecting biodiversity by developing bio-jobs: A multi-branch analysis with an application on French data

Jean De Beir, Céline Emond, Yannick L'Horty, Laetitia Tuffery

15-3. Profit-Sharing and Wages: An Empirical Analysis Using French Data Between 2000 and 2007

Noélie Delahaie, Richard Duhautois

15_2. A meta-regression analysis on intergenerational transmission of education: publication bias and genuine empirical effect

Nicolas Fleury, Fabrice Gilles

15_1. Why are there so many long-term unemployed in Paris?

Yannick L'Horty, Florent Sari 
14-14. Hiring discrimination based on national origin and the competition between employed and unemployed job seekers

Guillaume Pierné

14-13. Discrimination in Hiring: The curse of motorcycle women

Loïc Du Parquet, Emmanuel Duguet, Yannick L'Horty, Pascale Petit

14-12. Residential discrimination and the ethnic origin: An experimental assessment in the Paris suburbs

Emmanuel Duguet, Yannick L'Horty, Pascale Petit

14-11. Discrimination based on place of residence and access to employment Mathieu Bunel, Yannick L'Horty, Pascale Petit

14-10. Rural Electrification and Household Labor Supply: Evidence from Nigeria Claire Salmon, Jeremy Tanguy

14-9. Effects of immigration in frictional labor markets: theory and empirical evidence from EU countries

Eva Moreno-Galbis, Ahmed Tritah

14-8. Health, Work and Working Conditions: A Review of the European Economic Literature

Thomas Barnay

14-7. Labour mobility and the informal sector in Algeria: a cross-sectional comparison (2007-2012)

Philippe Adair, Youghourta Bellache

14-6. Does care to dependent elderly people living at home increase their mental health? Thomas Barnay, Sandrine Juin

14_5. The Effect of Non-Work Related Health Events on Career Outcomes: An Evaluation in the French Labor Market

Emmanuel Duguet, Christine le Clainche

14_4. Retirement intentions in the presence of technological change: Theory and evidence from France

Pierre-Jean Messe, Eva Moreno - Galbis, Francois-Charles Wolff

14_3. Why is Old Workers' Labor Market more Volatile? Unemployment Fluctuations over the Life-Cycle

Jean-Olivier Hairault, François Langot, Thepthida Sopraseuth

14_2. Participation, Recruitment Selection, and the Minimum Wage

Frédéric Gavrel

14_1. Disparities in taking sick leave between sectors of activity in France: a longitudinal analysis of administrative data

Thomas Barnay, Sandrine Juin, Renaud Legal 
13_9. An evaluation of the impact of industrial restructuring on individual human capital accumulation in France (1956-1993)

Nicolas Fleury, Fabrice Gilles

13_8. On the value of partial commitment for cooperative investment in buyer-supplier relationship

José de Sousa, Xavier Fairise

13-7. Search frictions, real wage rigidities and the optimal design of unemployment insurance

Julien Albertini, Xavier Fairise

13-6. Tax me if you can! Optimal non linear income tax between competing governments Etienne Lehmann, Laurent Simula, Alain Trannoy

13-5. Beyond the labour income tax wedge: The unemployment-reducing effect of tax progressivity

Etienne Lehmann, Claudio Lucifora, Simone Moriconi, Bruno Van Der Linden

13-4. Discrimination based on place of residence and access to employment

Mathieu Bunel, Emilia Ene Jones, Yannick L'Horty, Pascale Petit

12-3. The determinants of job access channels: evidence from the youth labor market in Franc

Jihan Ghrairi

13-2. Capital mobility, search unemployment and labor market policies: The case of minimum wages

Frédéric Gavrel

13-1. Effort and monetary incentives in Nonprofit et For-Profit Organizations Joseph Lanfranchi, Mathieu Narcy 
The CNRS Institute for Labor Studies and Public Policies (the TEPP Institute, FR n ${ }^{\circ} 3435$ CNRS) gathers together research centres specializing in economics and sociology:

- L'Equipe de Recherche sur l'Utilisation des Données Individuelles en lien avec la Théorie Economique (Research Team on Use of Individuals Data in connection with economic theory), ERUDITE, University of Paris-Est Créteil and University of ParisEst Marne-la-Vallée

- Le Centre d'Etudes des Politiques Economiques de l'université d'Evry (Research Centre focused on the analysis of economic policy and its foundations and implications), EPEE, University of Evry Val d'Essonne

- Le Centre Pierre Naville (Research on Work and Urban Policies), CPN, University of Evry Val d'Essonne

- Le Groupe d'Analyse des Itinéraires et des Niveaux Salariaux (Group on Analysis of Wage Levels and Trajectories), GAINS, University of the Maine

- Le Centre de Recherches en Economie et en Management, (Research centre in Economics and Management), CREM, University of Rennes 1 et University of Caen Basse-Normandie

- Le Groupe de Recherche ANgevin en Économie et Management (Angevin Research Group in Economics and Management), GRANEM, University of Angers ;

- Le Centre de Recherche en Economie et Droit (Research centre in Economics and Law) CRED, University of Paris II Panthéon-Assas ;

- Le Laboratoire d'Economie et de Management Nantes-Atlantique (Laboratory of Economics and Management of Nantes-Atlantique) LEMNA, University of Nantes ;

- Le Laboratoire interdisciplinaire d'étude du politique Hannah Arendt - Paris Est, LIPHA-PE

The TEPP Institute brings together 190 researchers and research professors and $140 \mathrm{PhD}$ students who study changes in work and employment in relation to the choices made by firms and analyse public policies using new evaluation methods. 